\title{
Investigating the role of interleukin-1 beta and glutamate in inflammatory bowel disease and epilepsy using discovery browsing
}

Thomas C. Rindflesch ${ }^{1}$, Catherine L. Blake², Michael J. Cairelli ${ }^{3}$, Marcelo Fiszman ${ }^{4}$, Caroline J. Zeiss ${ }^{5}$ and Halil Kilicoglu $6^{*}$ (1)

\begin{abstract}
Background: Structured electronic health records are a rich resource for identifying novel correlations, such as co-morbidities and adverse drug reactions. For drug development and better understanding of biomedical phenomena, such correlations need to be supported by viable hypotheses about the mechanisms involved, which can then form the basis of experimental investigations.

Methods: In this study, we demonstrate the use of discovery browsing, a literature-based discovery method, to generate plausible hypotheses elucidating correlations identified from structured clinical data. The method is supported by Semantic MEDLINE web application, which pinpoints interesting concepts and relevant MEDLINE citations, which are used to build a coherent hypothesis.
\end{abstract}

Results: Discovery browsing revealed a plausible explanation for the correlation between epilepsy and inflammatory bowel disease that was found in an earlier population study. The generated hypothesis involves interleukin-1 beta (IL-1 beta) and glutamate, and suggests that IL-1 beta influence on glutamate levels is involved in the etiology of both epilepsy and inflammatory bowel disease.

Conclusions: The approach presented in this paper can supplement population-based correlation studies by enabling the scientist to identify literature that may justify the novel patterns identified in such studies and can underpin basic biomedical research that can lead to improved treatments and better healthcare outcomes.

Keywords: Literature-based discovery, Discovery browsing, Epilepsy, Inflammatory bowel disease, Interleukin-1 beta, Glutamate

\section{Background}

Information needs in clinical setting and basic research setting differ significantly. Studies of information needs in clinical setting have focused on the types of questions asked by clinicians [1] and have informed the specific information facets (population, intervention, comparison, and outcome) that need to be identified in order to address those clinical questions [2]. In contrast to the clinical setting where there are often multiple studies relevant to the clinical encounter, scientists operate at the discovery end of the information synthesis spectrum where there

\section{*Correspondence: kilicogluh@mail.nih.gov}

${ }^{6}$ Lister Hill National Center for Biomedical Communications, U.S. National Library of Medicine, 8600 Rockville Pike, Bethesda, MD, USA

Full list of author information is available at the end of the article is less information available, and agreement on how to evaluate or combine findings from different studies is still under development [3]. In such an environment, a scientist begins with what is best described as a hypothesis projection, "the purely conjectural proliferation of a whole gamut of alternative explanatory hypotheses that are relatively plausible, a proliferation based on guesswork - though not 'mere' guesswork, but guesswork guided by a scientifically trained intuition. The aim of this enterprise is to identify those hypotheses that merit detailed scrutiny." [4]

Structured data from electronic health records (EHRs) are increasingly mined to identify novel correlations, such as disease co-occurrences or adverse drug reactions [5]. Such studies are sometimes highly localized, relying on 
data collected from a small set of institutions; thus, they can violate some of the key assumptions made when using traditional statistical measures to determine significance, leading to false positive associations [6]. When performed with population-level data (e.g., Medicare claims data), these data mining studies can provide epidemiological evidence for co-morbidities and other biomedical phenomena; however, they alone are unable to elucidate the mechanisms involved in such phenomena or offer plausible explanations. Such epidemiological evidence must be subjected to further analysis by scientists in order to generate viable hypotheses about the etiology of the observed correlations, a critical step for the development of safe and effective treatments.

In this paper, guided by statistical correlations extracted from structured EHR data, we show how a literaturebased discovery technique called discovery browsing $[7,8]$ can be used to support scientists as they explore hypothesis projections. This study was instigated to generate a hypothesis of mechanism for the results of a recent retrospective population study that measured the relationship between epilepsy and twelve autoimmune diseases [9]. That study analyzed health insurance claims data for 2,518,034 patients, both male and female, 65 years or younger. They reported that the risk of epilepsy was significantly heightened among patients with autoimmune disease. Collectively, individuals with autoimmune disease accounted for $17.5 \%$ of patients with epilepsy in the study population. This was a significant result that was not generally anticipated in the clinical community. The authors made several suggestive observations relevant to this correlation. Glutamate receptors may be involved in the etiology of epilepsy and other central nervous system disorders (the glutamate hypothesis) [10-12]. The inflammatory component of autoimmune diseases may be responsible for the occurrence of epilepsy [13, 14]. They did not, however, propose possible mechanisms underlying their findings and observations. Because there exists a lack of mechanistic understanding for the relationship between epilepsy and autoimmune disease, we view it as a prime candidate for discovery browsing. The suggestive observations mentioned above combined with our prior work that investigated the relationship between major depression and inflammation via cytokines using discovery browsing [7] indicated to us that focusing on glutamate and inflammation could be a fruitful avenue for a mechanistic understanding.

In this study, we focus on epilepsy and one autoimmune disorder, inflammatory bowel disease (IBD, a broader term covering both Crohn's disease and ulcerative colitis as included in Ong et al. [9]). Further, we look at interleukin-1 beta (IL-1 beta), as one of the principal substances (along with interleukin-6) involved in inflammation. We use discovery browsing to generate a hypothesis about the mechanisms of both IL-1 beta and glutamate, and suggest that the influence of the former on the latter is involved in the etiology of both IBD and epilepsy, thus proposing a mechanism for the observed connection between these two disorders. This study also investigates generalizability of previous work on discovery browsing. Instead of using discovery browsing to elucidate a general phenomenon that was observed in many different studies and known anecdotally for years (e.g., obesity paradox [8]), we apply it to a narrower scope, exploring possible mechanisms for the results of a single study without such an obvious presence in the clinical community.

\section{Related work \\ Discovery browsing}

Literature-based discovery (LBD) [15] is a method of hypothesis generation, the core premise of which is the so-called $A B C$ paradigm. $A B$ (a relationship between two terms $A$ and $B$ ) and $B C$ (a relationship between $B$ and C) are both known, but an AC relationship has so far not been proposed. The method can be used for open discovery, in which the discovery (or hypothesis) AC is the result. Alternatively, in closed discovery, $\mathrm{AC}$ may be known (or assumed) and relations $\mathrm{AB}$ and $\mathrm{BC}$ are sought to posit $\mathrm{B}$ as an explanation for $\mathrm{AC}$ (or a mechanistic link between the two concepts). While LBD research has predominantly focused on biomedical literature, it has also been applied to other domains, such as humanities [16], world wide web [17], as well as technology and social issues [18].

Wilkowski et al. [7] introduced discovery browsing as a modification of LBD. They described it as a tool for illuminating under-studied and poorly understood phenomena rather than necessarily for making discoveries. Discovery browsing also relies on the $\mathrm{ABC}$ paradigm and the relationships it exhibits; however, the researcher may assume (or already know) the relationships, but seek to elucidate the details of these assumptions, hypotheses, or known relationships. In the current study, we consider the relationships to be IBD (A) - inflammation (B) - epilepsy (C), in which $A B, B C$, and $A C$ have all been proposed. We then seek to investigate, expand, and elucidate the $B$ relationship between these two diseases for a finer-grained understanding of the mechanisms involved.

Wilkowski et al. [7] used discovery browsing to look at the interaction of melatonin, cytokines, and major depression. Cairelli et al. [8] formalized the method and exploited it to investigate why obesity is beneficial in intensive care, but detrimental otherwise (i.e. obesity paradox).

\section{SemRep}

Semantic predications extracted from MEDLINE citations (titles and abstracts) naturally correlate with relations in the $\mathrm{ABC}$ paradigm and underpin this study. A semantic 
predication is a formal representation of an assertion made in text. Such structures provide a type of computable knowledge representing the information in the text from which they are extracted. For example, the predication "Interleukin-1 beta-CAUSES-Seizures" represents part of the meaning of the sentence, "In addition, high $I L$ 1 beta doses induced seizures only in IL-1beta receptorexpressing mice" (mentions relevant to the predication in bold). Note that it does not (necessarily) summarize an entire sentence, and in this case does not contain the information limiting the seizure induction to IL-1 beta receptor-expressing mice. A semantic predication consists of a predicate (CAUSES in this example) and arguments (Interleukin-1 beta and Seizures).

We extract predications using the SemRep natural language processing system [19]. SemRep inspects each sentence of input text to identify predications asserted in each sentence. The system depends on domain knowledge in the Unified Medical Language System (UMLS) developed by the U.S. National Library of Medicine [20, 21]. A SemRep predication has UMLS Metathesaurus concepts as arguments and a UMLS Semantic Network relation as predicate.

Extracted predications may be filtered by using automatic abstraction summarization [22] to focus on specific aspects of biomedicine, such as treatment of diseases or pharmacogenomics. In this study, we used this process to focus on predications asserting core relations in molecular biology [23]. We used the following meta-predications, where the arguments are represented as general semantic classes:

- \{Substance $\}$ ASSOCIATED_WITH OR PREDISPOSES OR CAUSES \{Pathology\}

- \{Substance\} INTERACTS_WITH OR INHIBITS OR STIMULATES \{Substance\}

- $\{$ Substance\} AFFECTS OR DISRUPTS OR AUGMENTS \{Anatomy OR Process\}

- $\{$ Anatomy OR Living Being\} LOCATION_OF \{Substance $\}$

- $\{$ Anatomy\} PART_OF \{Anatomy OR Living Being\}

- \{Process\} PROCESS_OF \{Living Being\}

\section{Semantic MEDLINE}

The methodology pursued in this study is implemented with Semantic MEDLINE [24], a Web application that integrates PubMed document retrieval, SemRep natural language processing, automatic abstraction summarization, and visualization into a single Web portal. SemRep predications extracted from all MEDLINE citations are made available from SemMedDB [25] and are summarized according to the meta-predications just noted. Summarized predications are then presented as a connected interactive graph of semantic relations (Fig. 1). Subjects and objects are nodes in the graph, while predicates are edges. By clicking on an edge, the user can see the predication represented. The edge has a link to the

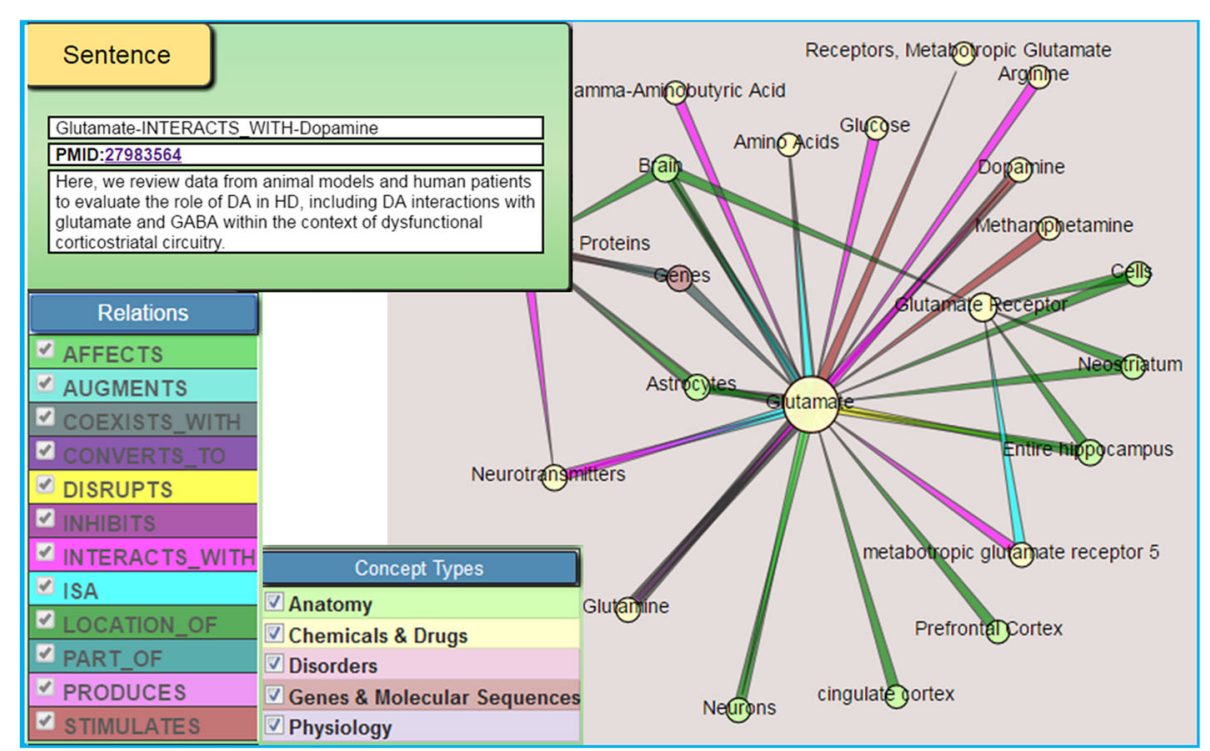

Fig. 1 Illustration of the Semantic MEDLINE web application. The summarized results of a PubMed search are displayed as an interactive graph, where nodes represent subjects and objects of semantic predications and the edges represent the predicates (right). Edges are linked to the original MEDLINE citation from which the predication is extracted (top-left). Nodes and edges can be filtered using relation and semantic group filters (bottom-left) 
original MEDLINE citation from which the predication is extracted.

Semantic MEDLINE supports discovery browsing by presenting relationships to the user that might not have been noticed without it. Miller et al. [26] used Semantic MEDLINE to study the effect of the interaction of testosterone and cortisol on declining sleep quality in aging men. In related work, Cohen et al. [27] discussed EpiphaNet, which displays SemRep predications in graphical form for literature-based discovery. Hristovski et al. [28] described several Semantic MEDLINE-based systems designed to facilitate discovery.

Other literature-based exploration and discovery systems have also been proposed to formulate and assess scientific hypotheses. For example, Arrowsmith [29] links two sets of articles from biomedical literature using title words and phrases and statistical information. In a similar vein, LitLinker [30] performs open discovery using UMLS concepts identified by MetaMap [31] as the basis, grouping and pruning them in conjunction with statistical correlations. Berlanga et al. [32] focus on semantic integration and visualization from multiple knowledge and data sources, using named entity recognition to recognize concepts, exploiting concept taxonomies and co-occurrence across documents to identify interesting associations and visualize them for exploration purposes. HyQue [33] is concerned with semantic integration for the purpose of hypothesis evaluation and uses Semantic Web technologies to standardize representation of input, knowledge sources, data, queries, and outputs. Unlike SemRep, these systems/tools do not perform explicit relation extraction, mainly relying on concept co-occurrence or manually curated relationships.

\section{Inflammation, epilepsy, and inflammatory bowel disease}

Before investigating possible mechanistic connections between IBD and epilepsy, we surveyed MEDLINE regarding the observations from Ong et al. [9] to determine how much research has been published concerning this relationship. We began by looking at IBD, a disorder in which the involvement of inflammation is not controversial.

In order to focus relevant background information, we used Semantic MEDLINE as an adjunct to PubMed to query MEDLINE for the primary proinflammatory cytokines involved in IBD. We issued the Semantic MEDLINE query "inflammatory bowel disease" on 03/22/2017 and restricted results to the most recent 500 citations. 4402 predications were extracted and we restricted these to the core relations in molecular biology. The following cytokines appear as nodes in the graph: IL-1 alpha, IL-1 beta, IL-6, IL-10, IL-17, IL-18, IL-19, and IL-23. We then used PubMed to determine the amount of research for each of these substances in association with IBD. In order to achieve high recall, we combined the search for IL-1 alpha and IL-1 beta with the query ("interleukin-1" AND "inflammatory bowel disease"). All other cytokines in this list were queried with the form (" $<$ IL-X $>$ " AND "inflammatory bowel disease"). The query results were: IL-1: 340 MEDLINE citations; IL-6: 779; IL-10: 841; 1L-17: 348; IL-18: 106; IL-19: 10; IL-23: 228.

In order to determine which cytokines are most prominently involved in both IBD and epilepsy, we then repeated this series of queries to PubMed, substituting "epilepsy" for "inflammatory bowel disease". The results for each query were: IL-1: 201 MEDLINE citations; IL-6: 216; IL-10: 71; IL-17: 19; IL-18: 14; IL-23: 4; and no citations retrieved for IL-19. Although several cytokines are prominent in IBD research, only IL-1 (mostly beta) and interleukin- 6 have been much studied with respect to epilepsy. The inflammatory aspects of both conditions are accompanied by alterations in a broad array of mediators (see Bevivino and Monteleone [34] and Matin et al. [35] for reviews on IBD and epilepsy, respectively) whose interaction in disease etiology is likely to be contextual. While both IL- 1 beta and interleukin- 6 were promising candidates for discovery browsing, we focused on IL-1 beta in this paper, partly to keep the scope of this work manageable. This procedure could be repeated with other substances, especially interleukin-6, to potentially reveal additional insights.

As further background investigation, we used PubMed to get an overview of research on IL-1 beta and IBD. We looked at a sample from the 340 citations returned with the query noted above. IL-1 beta has long been associated with gastrointestinal disturbances (e.g. [36]) and with IBD in particular (e.g. [37]). Subsequent research has looked at various aspects of that association. For example, Casellas et al. [38] investigated the role of IL-1 beta in chronic ulcerative colitis. Heresbach et al. [39] sought to elucidate genetic susceptibility to IBD, concentrating on IL-1beta and IL-1 receptor antagonist (IL-1ra) gene polymorphisms. Coccia et al. [40] reported on multiple mechanisms through which IL-1 beta contributes to intestinal pathology. Li et al. [41] exploited bioluminescence imaging to determine the location of cells producing IL-1 beta during intestinal inflammation. Das [42] hypothesized that the etiology of IBD is due to inadequate production of inflammation resolving molecules, such as lipoxins, resolvins, protectins, maresins and nitrolipids.

Finally, we queried PubMed to determine whether there is any research on IL-1 beta and both IBD and epilepsy. The query ("interleukin 1" AND ("inflammatory bowel disease" OR colitis) AND (seizure OR epilepsy)) returned only 1 citation [43], a review which states in the abstract, foreshadowing the conclusions of Ong et al. [9], that "There are reports suggesting more predispositions 
to seizures during inflammatory conditions like colitis, pneumonia and rheumatoid arthritis."

We then moved on to the focus of the paper, which was twofold: 1) investigate the research on IL-1 beta and epilepsy, and 2) look at possible mechanistic connections between IBD and epilepsy involving inflammation (IL-1 beta).

\section{Methods}

At the core of the discovery browsing methodology pursued in this study is cooperative reciprocity between the system and the user's domain knowledge. This takes the form of the user issuing an initial query to Semantic MEDLINE reflecting an area of interest. All queries were issued at the end of March, 2017. The graph resulting from each query was inspected for concepts (either in the predications or in the abstracts from which they are extracted) that capture the attention of the researcher and which may incite the development of a potential hypothesis regarding the study being pursued. At this point, PubMed was consulted (using the same query) to determine whether any citation from which Semantic MEDLINE did not extract a predication supported the viability of the hypothesis being developed. This step is performed in part to address recall problems of SemRep, which may result in missing information important for hypothesis generation. If the developing hypothesis was supported, it was pursued with another query to Semantic MEDLINE incorporating the concept of interest, and the process was repeated until we were satisfied with a coherent argumentation chain. Finally, PubMed was searched to determine whether the hypothesis generated is novel. Figure 2 provides an overview of the method.
For each query to Semantic MEDLINE, we limited the abstracts returned to the most recent 500 , although fewer total abstracts were retrieved for some queries. The predications extracted were then summarized using the meta-predications given in previous section. For ease of inspection, we further limited the graph for each query to a maximum of 50 nodes and 100 edges; nodes are ranked by frequency and the graph is limited to 50 nodes with the highest frequency.

\section{Results}

\section{IL-1 beta and epilepsy}

The initial query to Semantic MEDLINE was ("interleukin 1" AND (epilepsy OR seizure)), which returned 2481 predications extracted from 240 citations. In the summarized graph, several predications were considered noteworthy as indicating a relationship between IL-1 beta and epilepsy. "Interleukin-1 beta-AFFECTS-Seizure" was extracted from Vezzani et al. [44], which reports that intrahippocampal application of recombinant IL-1ra inhibits seizures experimentally induced by bicuculline methiodide in rodents. This study cites previous work [45], in which they found that exogenous application of IL-1 beta in the rat hippocampus prolongs kainite-induced seizure by enhancing glutamatergic neurotransmission.

The predication "Interleukin-1 beta-CAUSES-Seizures" was extracted from two citations. In one, Ravizza and Vezzani [46] conducted immunohistochemical analysis of tissue following acute electrical stimulation in the ventral hippocampus of rats. They investigated the role of IL-1 beta during resulting epileptic activity, focusing on the role of IL-1 receptor type 1 (IL-1R1) in rat forebrain. They suggest that this receptor plays different roles in neurons and in astrocytes during status epilepticus. Another study

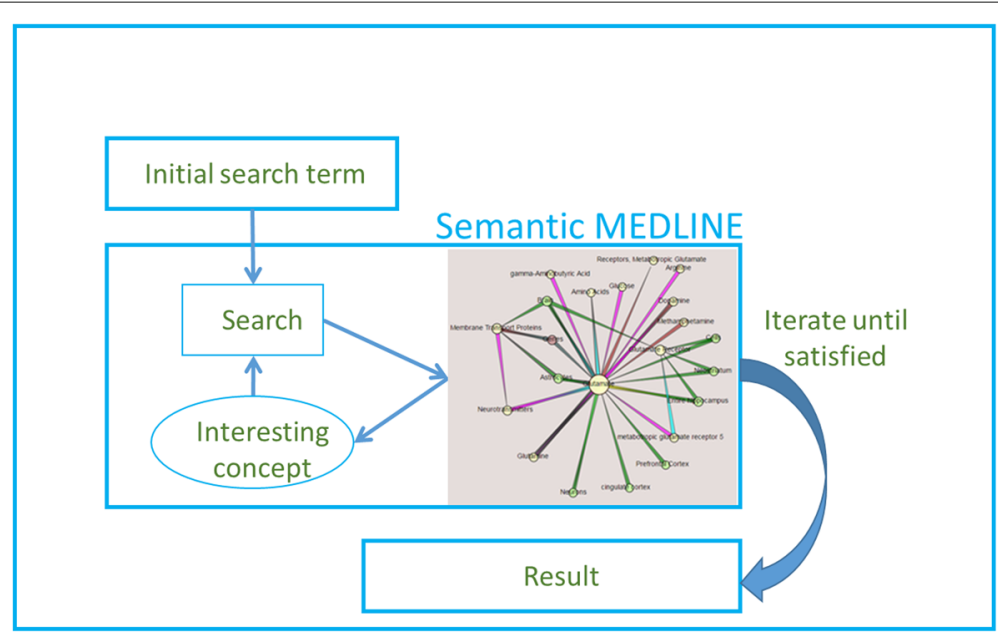

Fig. 2 Overview of discovery browsing. An iterative process that incorporates Semantic MEDLINE help identify interesting concepts, which are used to build an argumentation chain 
[47] looked at the mechanism of seizure by injecting the right lateral ventricle of rats with both IL-1 beta and glutamate. They conclude that there is an interaction between IL-1 beta (through the IL-1 receptor) and metabotropic $g$ lutamate receptors in the onset of epilepsy. "Interleukin-1 beta-AUGMENTS-Status Epilepticus" was extracted from Pernot et al. [48], in which the relationship between neuroinflammation and mesiotemporal lobe epilepsy syndrome was explored with immunohistochemical analysis of tissue after mesiotemporal lobe epilepsy syndrome was experimentally induced in C57BL/6 adult mice by the unilateral intrahippocampal injection of kainate. They conclude that neuroinflammatory pathways are associated with epileptogenesis.

Opposing results have also been published. One such study, Claycomb et al. [49] (from which the predication "Interleukin-1 beta-ASSOCIATED_WITH-Seizures" was extracted), reports that IL-1 beta is neuroprotective. This study was conducted on transgenic mice with targeted disruption in genes for either the ligand IL-1 beta or its signaling receptor, IL-IR1. Their claim is based on their finding that chemoconvulsants administered to IL-1 beta and IL-1R1 -/- mice produced more acute seizures than in their respective $+/+$ littermates. It is not clear that these results would generalize to animals without such genetic manipulation. See Table 1 for an overview of our results on IL-1 beta and epilepsy.

Since we saw considerable research implicating IL-1 beta in epileptogenesis, we next pursued the potential interaction of IL-1 beta and glutamate in the pathogenesis of epilepsy and seizures $[45,47]$. We began by looking for research that examined glutamate and epilepsy without considering IL-1 beta, and then looked at the interaction of the two in epilepsy and seizure.

\section{Glutamate and epilepsy}

The Semantic MEDLINE query (glutamate AND (epilepsy OR seizure)) extracted 5170 predications from the most recent 500 citations. After summarization, we examined several predications which appeared to be relevant to glutamate in the context of seizure or epilepsy. Juhasz et al. [50] used proton magnetic resonance spectroscopic imaging to test glutamate concentration levels in epileptic children with Sturge-Weber syndrome (which is strongly associated with epilepsy [51]). They found increased glutamate in the affected hemisphere, which they interpret as support for the role of excess glutamate in these patients ("Glutamate-ASSOCIATED_WITH-Seizures"). Cavus et al. [52] measured glutamate levels in epileptic and nonepileptic cortical sites in 79 patients with refractory epilepsy using high-performance liquid chromatography. They found elevated extracellular glutamate at epileptogenic as compared to nonepileptogenic sites ("GlutamateASSOCIATED_WITH-Epilepsy").

In considering MEDLINE citations from which Semantic MEDLINE did not extract a predication, one notable paper discusses research on the mechanisms of glutamate involvement in epilepsy. Perez et al. [53] assume that excessive glutamate underlies refractory temporal lobe epilepsy. They investigated the cause by using immunogold electron microscopy to measure glutamate levels in tissue extracted from the brains of male Sprague-Dawley rats infused with methionine sulfoximine, which induces glutamine synthetase efficiency. They conclude that such deficiency leads to increased extracellular glutamate. The studies we report on glutamate and epilepsy are summarized in Table 2.

Based on research indicating glutamate involvement in epilepsy and considering research implicating IL-1 beta

Table 1 Summary of articles discussing IL-1 beta and epilepsy

\begin{tabular}{|c|c|c|c|}
\hline Study & Subjects & Method & Result/Conclusion \\
\hline Vezzani et al. [45] & Kainite-intoxicated rats & $\begin{array}{l}\text { Application of IL-1 beta in the } \\
\text { hippocampus }\end{array}$ & $\begin{array}{l}\text { IL-1 beta prolongs experimentally } \\
\text { induced seizures }\end{array}$ \\
\hline Vezzani et al. [44] & $\begin{array}{l}\text { Bicuculline methiodide-intoxicated } \\
\text { rodents }\end{array}$ & $\begin{array}{l}\text { Intrahippocampal application of } \\
\text { recombinant IL-1ra }\end{array}$ & $\begin{array}{l}\text { IL-1ra inhibits experimentally } \\
\text { induced seizures }\end{array}$ \\
\hline Ravizza and Vezzani [46] & Male Sprague-Dawley rats & $\begin{array}{l}\text { Immunohistochemical analysis } \\
\text { following acute electrical } \\
\text { stimulation in the ventral } \\
\text { hippocampus }\end{array}$ & $\begin{array}{l}\text { IL-1R1 plays different roles in } \\
\text { neurons and in astrocytes during } \\
\text { status epilepticus }\end{array}$ \\
\hline Wang et al. [47] & Rats & $\begin{array}{l}\text { Injection of right lateral ventricle } \\
\text { with both IL-1 beta and glutamate }\end{array}$ & $\begin{array}{l}\text { Interaction between } \mathrm{IL}-1 \text { beta and } \\
\text { metabotropic glutamate receptors } \\
\text { in the onset of epilepsy }\end{array}$ \\
\hline Pernot et al. [48] & C57BL/6 adult mice & $\begin{array}{l}\text { Immunohistochemical analysis of } \\
\text { tissue after mesiotemporal lobe } \\
\text { epilepsy syndrome induced by } \\
\text { intrahippocampal injection of } \\
\text { kainate }\end{array}$ & $\begin{array}{l}\text { Neuroinflammatory pathways are } \\
\text { associated with epileptogenesis }\end{array}$ \\
\hline Claycomb et al. [49] & IL-1 beta and IL1R1 -/- mice & $\begin{array}{l}\text { Administration of } \\
\text { chemoconvulsants }\end{array}$ & Produced more acute seizures \\
\hline
\end{tabular}


Table 2 Summary of articles discussing glutamate and epilepsy

\begin{tabular}{llll}
\hline Study & Subjects & Method & Result/Conclusion \\
\hline Juhász et al. [50] & Epileptic children with Sturge-Weber & $\begin{array}{l}\text { Proton magnetic resonance spectro- } \\
\text { scopic brain imaging }\end{array}$ & $\begin{array}{l}\text { Increased glutamate concentrations } \\
\text { observed }\end{array}$ \\
Syndrome & $\begin{array}{l}\text { Epileptic and nonepileptic corti- } \\
\text { cal sites in patients with refractory } \\
\text { epilepsy }\end{array}$ & $\begin{array}{l}\text { High-performance liquid chromatog- } \\
\text { raphy based on microdialysis probes }\end{array}$ & $\begin{array}{l}\text { Elevated extracellular glutamate } \\
\text { observed at epileptogenic sites }\end{array}$ \\
& $\begin{array}{l}\text { Tissue extracted from brains of male } \\
\text { Perez et al. [53] }\end{array}$ & $\begin{array}{l}\text { Glutamate levels measured with Glutamine synthetase deficiency } \\
\text { methionine sulfoximine }\end{array}$ & $\begin{array}{l}\text { leads to increased extracellular } \\
\text { glutamate }\end{array}$ \\
\hline
\end{tabular}

in epilepsy, we were encouraged to investigate the interaction of IL-1 beta and glutamate in the context of this disorder.

\section{IL-1 beta and glutamate}

We issued three queries to Semantic MEDLINE to investigate the relationship of IL- 1 beta and glutamate in the etiology of epilepsy. One focused on this disorder (and seizure), another specified the brain (but not the disorder), and a third specified neither disorder nor anatomic location.

\section{And epilepsy}

The query ("interleukin-1" AND glutamate AND (seizure OR epilepsy)) retrieved 18 citations and 202 predications, which were not summarized. Two papers identified in the graph were relevant. Xiaoqin et al. [54] injected the cerebral cortex and hippocampus of rats with IL-1 beta and IL-6. Immunohistochemistry observation revealed the development of seizures along with increased glutamate and decreased GABA ("Interleukin-6-CAUSESSeizures"). Donnelly et al. [55] analyzed synaptosomes prepared from the brains of BALB/c female mice, 8-12 weeks old, in which epilepsy-like symptoms had been induced with glycerol. Synaptosome pellets were then subjected to a series of in vitro techniques after which they observed an increase in IL-1 beta levels and a decrease in glutamate release in hippocampus tissue ("Entire hippocampus-LOCATION_OF-Glutamate").

\section{In the brain}

The Semantic MEDLINE query ("interleukin 1" AND glutamate AND brain) returned 1850 predications from 160 citations. After summarization, several predications were extracted from citations discussing the interaction of IL-1 beta and glutamate. "Interleukin-1 beta-DISRUPTSuptake" was extracted from an article [56], which reported that astrocyte uptake of glutamate is neuroprotective during brain inflammation. Based on Northern blot analysis and other in vitro techniques performed on primal human astrocyte cultures subjected to several cytokines and $3 \mathrm{H}$-glutamate, the authors concluded that proinflammatory cytokines inhibit astrocyte glutamate uptake.
Based on intracerebral microdialysis in unanesthetized rabbits, Huang et al. [57] reported that organum vasculosum laminae terminalis (OVLT) release of glutamate was induced by intracerebroventricular injection of IL-1beta ("Interleukin-1 beta-STIMULATES-Glutamate").

When inspecting citations from which Semantic MEDLINE did not extract a predication, we found an earlier report which concluded that IL-1 beta enhances glutamate. As measured by brain microdialysis in freely moving male Sprague-Dawley rats, Mascarucci et al. [58] found that injection of intraperitoneal IL-1 beta increased glutamate release in the nucleus tractus solitarius.

Some studies reported that IL-1 beta inhibits glutamate. Murray et al. [59] prepared hippocampal synaptosomes from male Wistar rats, on which in vitro experiments were conducted. They reported that immunoblotting with specific antibody revealed that IL-1 beta inhibited potassium chloride-stimulated glutamate release in tissue from young (4 month) but not older (22 month) rats, and only in the presence of calcium ("Interleukin-1 beta-STIMULATES-Glutamate" (although the predication itself is wrong)). In a study of the influence of IL-1 beta on memory consolidation, Gonzalez et al. [60] reported that intrahippocampal injection of IL-1 beta in adult male Wistar rats decreases glutamate release from dorsal hippocampus synaptosomes after contextual fear conditioning ("Interleukin-1 beta-INTERACTS_WITHCRK protein, human"). The studies resulting from this query (including "brain") and the previous one (not including "brain") are given in Table 3.

\section{Disorder and location not specified}

The Semantic MEDLINE query ("interleukin 1" AND glutamate) retrieved 3232 predications from 289 citations. The research we saw in the summarized graph focused on neuronal involvement. For example, the predication "Glutamate-COEXISTS_WITH-Interleukin-1 beta" was extracted from Casamenti et al. [61], which looked at the involvement of inflammation with Alzheimer's disease. IL-1 beta was injected into the nucleus basalis of adult male Wistar rats. The authors reported a marked increase in glutamate (revealed through microdialysis). 
Table 3 Summary of articles discussing IL-1 beta and glutamate

\begin{tabular}{|c|c|c|c|}
\hline Study & Subjects & Method & Result/Conclusion \\
\hline Xiaoqin et al. [54] & $\begin{array}{l}\text { Cerebral cortex and hippocampus } \\
\text { of rats }\end{array}$ & $\begin{array}{l}\text { Injection of } \mathrm{IL}-1 \text { beta and } \mathrm{IL}-6 \text {; } \\
\text { immuno-histochemistry }\end{array}$ & $\begin{array}{l}\text { Increased glutamate and decreased } \\
\text { GABA observed }\end{array}$ \\
\hline Donnelly et al. [55] & $\begin{array}{l}\text { Synaptosome pellets prepared } \\
\text { from brains of } 8-12 \text { week-old } \\
\text { BALB/c female mice intoxicated } \\
\text { with glycerol }\end{array}$ & In vitro techniques & $\begin{array}{l}\text { Report increased } \mid \mathrm{L}-1 \text { beta levels } \\
\text { and decreased glutamate release in } \\
\text { hippocampus tissue }\end{array}$ \\
\hline Hu et al. [56] & $\begin{array}{l}\text { Human astrocyte cultures sub- } \\
\text { jected to several cytokines and } \\
\text { 3H-glutamate }\end{array}$ & $\begin{array}{l}\text { Northern blot analysis and other in } \\
\text { vitro techniques }\end{array}$ & $\begin{array}{l}\text { Proinflammatory cytokines inhibit } \\
\text { astrocyte glutamate uptake }\end{array}$ \\
\hline Huang et al. [57] & $\begin{array}{l}\text { Intracerebroventricular injection of } \\
\text { IL-1 beta in adult male New Zealand } \\
\text { white rabbits }\end{array}$ & Intracerebral microdialysis & Glutamate induced by IL-1 beta \\
\hline Mascarucci et al. [58] & $\begin{array}{l}\text { Intraperitoneal injection of IL-1 beta } \\
\text { in freely moving male Sprague- } \\
\text { Dawley rats }\end{array}$ & Brain microdialysis & $\begin{array}{l}\text { Increased glutamate released in the } \\
\text { nucleus tractus solitarius }\end{array}$ \\
\hline Murray et al. [59] & $\begin{array}{l}\text { Synaptosomes prepared from male } \\
\text { Wistar rats }\end{array}$ & $\begin{array}{l}\text { Immunoblotting with specific anti- } \\
\text { body }\end{array}$ & $\begin{array}{l}\text { IL-1 beta inhibits potassium } \\
\text { chloride-stimulated glutamate } \\
\text { release in tissue from young ( } 4 \\
\text { month), in the presence of calcium }\end{array}$ \\
\hline Gonzalez et al. [60] & Adult male Wistar rats & $\begin{array}{l}\text { Intrahippocampal injection of } \mathrm{IL}-1 \\
\text { beta; preparation of synaptosomes; } \\
\text { in vitro technique to assay gluta- } \\
\text { mate release }\end{array}$ & $\begin{array}{l}\text { IL-1 beta decreases glutamate } \\
\text { release from dorsal hippocampus } \\
\text { synaptosomes after contextual fear } \\
\text { conditioning }\end{array}$ \\
\hline
\end{tabular}

The query which retrieved the first two studies used the term "brain", and that which retrieved the other studies used the term "epilepsy")

Prow and Irani [62] used immunoblotting and immunohistochemistry, cytokine assays, and histological analysis to examine spinal cord tissue extracted from mice challenged with neuroadapted Sindbis virus. Based on analysis of levels of astroglial glutamate transporter (which removes glutamate from the synaptic cleft), IL-1 beta, and glutamate, they claimed that the increase of IL-1 beta in response to the virus disrupts glutamate homeostasis. They concluded (in the abstract) that their data "provide one of the strongest in vivo links between innate immune responses and the development of excitotoxicity demonstrated to date." ("Interleukin-1 betaINTERACTS_WITH-Glutamates").

In a sample of citations from which Semantic MEDLINE did not extract a predication, Fogal et al. [63], for example, investigated the etiology of hypoxic-ischemic brain damage in IL-1R1 null mutant, mGluR1-/-, and wild-type control mice. From both in vitro and in vivo experiments, they concluded that IL-1 beta makes a significant contribution to such neuronal injury and that it increases extracellular glutamate as part of the mechanism. Yan and Weng [64] used both in vitro and in vivo techniques to study the mechanisms by which IL-1 beta interacts with glutamate in neuropathic pain experimentally induced in young adult male Sprague-Dawley rats. They concluded that IL-1 beta uses presynaptic NMDA receptors to enhance glutamate release from primary afferents in neuropathic rats. Yan et al. [65] analyzed tissue extracted from young adult male Sprague-Dawley rats subjected to partial sciatic nerve ligation. Based on several in vitro techniques to determine the mechanisms involved, they concluded that IL-1 beta contributes to neuropathic pain by suppressing glial glutamate uptake. The research reported in this section is summarized in Table 4.

After having seen considerable research suggesting that IL-1 beta may increase glutamate, facilitate its receptors, or inhibit its uptake by glial cells in the context of epilepsy and other neuronal disturbances, we turned to glutamate and IBD.

\section{Glutamate and inflammatory bowel disease}

In order to investigate glutamate and gastrointestinal phenomena, we issued two queries to Semantic MEDLINE, one focused on anatomy and another on disease. The anatomy-focused query (glutamate AND (bowel OR colon OR intestine OR gastrointestinal OR stomach)) retrieved 4718 predications from 500 citations. Many of these discuss the relevance of normal levels of glutamate and its receptors to gastrointestinal processes. For example, two recent reviews highlight the prominence of glutamatergic phenomena underpinning the mechanisms of gastrointestinal functions. The predication "Gut-LOCATION_OF-Glutamate" was extracted from Julio-Pieper et al. [66], which states that glutamate is the main neurotransmitter of the brain-gut axis (realized in part by the vagus nerve). (Metabotropic) glutamate receptors occur in the brain as well as throughout the gastrointestinal tract, from the mouth to the large 
Table 4 Summary of articles discussing IL-1 beta and glutamate (disorder and location not specified in query)

\begin{tabular}{|c|c|c|c|}
\hline Study & Subjects & Method & Result/Conclusion \\
\hline Casamenti et al. [61] & Adult male Wistar rats & $\begin{array}{l}\text { IL-1 beta injected into nucleus } \\
\text { basalis; microdialysis }\end{array}$ & Significant increase in glutamate \\
\hline Prow and Irani [62] & $\begin{array}{l}\text { Spinal cord tissue extracted from } \\
\text { mice challenged with neuroad- } \\
\text { apted Sindbis virus }\end{array}$ & $\begin{array}{l}\text { Immunoblotting and immunohis- } \\
\text { tochemistry, cytokine assays, and } \\
\text { histological analysis }\end{array}$ & $\begin{array}{l}\text { Increase of } \mathrm{IL}-1 \text { beta in response } \\
\text { to the virus disrupts glutamate } \\
\text { homeostasis (development of } \\
\text { excitotoxicity) }\end{array}$ \\
\hline Fogal et al. [63] & $\begin{array}{l}\text { IL-1RI null mutant, mGluR1-/-, and } \\
\text { wild-type control mice }\end{array}$ & $\begin{array}{l}\text { Both in vitro and in vivo experi- } \\
\text { ments }\end{array}$ & $\begin{array}{l}\text { IL-1 beta increases extracellular } \\
\text { glutamate as part of the } \\
\text { mechanism of neuronal injury }\end{array}$ \\
\hline Yan and Weng [64] & $\begin{array}{l}\text { Young adult male Sprague-Dawley } \\
\text { rats }\end{array}$ & $\begin{array}{l}\text { In vitro and in vivo techniques to } \\
\text { study experimentally induced neu- } \\
\text { ropathic pain }\end{array}$ & $\begin{array}{l}\text { IL-1 beta enhances glutamate } \\
\text { release from primary afferents }\end{array}$ \\
\hline Yan et al. [65] & $\begin{array}{l}\text { Tissue from young adult male } \\
\text { Sprague-Dawley rats subjected to } \\
\text { partial sciatic nerve ligation }\end{array}$ & Several in vitro techniques & $\begin{array}{l}\text { IL-1 beta contributes to } \\
\text { neuropathic pain by suppressing } \\
\text { glial glutamate uptake }\end{array}$ \\
\hline
\end{tabular}

intestine, and are relevant to digestion as a whole. These receptors are involved in several gastrointestinal reflexes, including swallowing, gastric accommodation, and emesis [67].

In one of the citations retrieved with PubMed that did not produce a SemRep predication, Clarke et al. [68] investigated the kynurenine pathway of tryptophan degradation in plasma samples from 10 male patients with irritable bowel syndrome (IBS) and 26 controls. High performance liquid chromatography revealed that concentration of the neuroprotective metabolite kynurenic acid (an antagonist of the NMDA glutamate receptor) was decreased in the IBS subjects.

The disease-focused query (glutamate AND ("inflammatory bowel disease" OR colitis)) retrieved 995 predications from 89 citations. In the summarized graph, "Colitis-PROCESS_OF-Rattus norvegicus" was extracted from Varga et al. [69]. In this study, kynurenic acid, an antagonist of NMDA (a glutamate receptor), was administered to male Wistar rats after inducing colonic inflammation with trinitrobenzene sulfonic acid. Measurements conducted on anesthetized animals as well as on blood samples and colon biopsies indicated a significant modulatory effect, including reduced inflammatory enzyme activities, decreased intestinal motility, and increased tone of the colon.

Several of the MEDLINE citations from which Semantic MEDLINE did not extract a predication report an association between glutamate and intestinal phenomena. For example, Carpanese et al. [70] conducted a study based on in vitro cell cultures from adult male rats. Based on immunocytochemistry, they conclude that blockade of glutamate receptors (NMDA and AMPA/kainite) may protect enteric neurons subjected to in vitro chemically-induced ischemic injury followed by reperfusion.

We then sought additional information on kynurenic acid and its potential role in mitigating gastrointestinal disturbances. The PubMed query, (("kynurenic acid" OR kynurenine) AND "inflammatory bowel disease") returned 7 citations. One of these was Forrest et al. [71], in which serum concentrations of purines and kynurenines were measured in patients with mild IBD. In noting increased levels of kynurenic acid compared to controls, they concluded that kynurenine modulation of glutamate receptors is involved in the symptoms of IBD, either as a response to an abnormality or as a primary abnormality itself. The studies we cite on glutamate and IBD are given in Table 5.

Finally, we issued two PubMed queries, one diseasefocused and a second anatomy-focused, to look for research reporting on the interaction of IL-1 beta and glutamate in IBD. The first, (interleukin-1 AND glutamate AND ("inflammatory bowel disease" or colitis)), returned no citations. The second, (interleukin-1 AND glutamate AND (bowel OR colon OR intestine OR gastrointestinal OR stomach)), retrieved three citations, none of which discuss the interaction of IL-1 beta and glutamate in the etiology of gastrointestinal disorders. Saperas et al. [72] discuss a possible effect of IL-1 beta on gastric acid secretion but do not mention the interaction of interleukin-1 beta and glutamate. Morrow et al. [73] investigated the effect of murine IL-1 beta on gastric contractility, but did not address the relation of IL-1 beta and glutamate in IBD. Finally, Qu et al. [74] present a review of epigenetic phenomena in gastric cancer. As part of the discussion, IL-1 beta and glutamate are mentioned, but their interaction in IBD is not addressed. 
Table 5 Summary of articles discussing glutamate and inflammatory bowel disease

\begin{tabular}{|c|c|c|c|}
\hline Study & Subjects & Method & Result/Conclusion \\
\hline Clarke et al. [68] & $\begin{array}{l}\text { Male patients with irritable bowel } \\
\text { syndrome and healthy controls }\end{array}$ & $\begin{array}{l}\text { High performance liquid chromato- } \\
\text { graphy on plasma samples }\end{array}$ & $\begin{array}{l}\text { Kynurenic acid was decreased in } \\
\text { patients with disease }\end{array}$ \\
\hline Varga et al. [69] & $\begin{array}{l}\text { Male Wistar rats after inducing } \\
\text { colonic inflammation with TNBS }\end{array}$ & $\begin{array}{l}\text { Measurements on anesthetized ani- } \\
\text { mals and on blood samples and } \\
\text { colon biopsies after administration } \\
\text { of kynurenic acid }\end{array}$ & $\begin{array}{l}\text { Reduced inflammatory enzyme } \\
\text { activities, decreased intestinal } \\
\text { motility, and increased tone of the } \\
\text { colon }\end{array}$ \\
\hline Carpanese et al. [70] & $\begin{array}{l}\text { Enteric neuron cultures from adult } \\
\text { male rats }\end{array}$ & $\begin{array}{l}\text { In vitro ischemic injury; reperfusion; } \\
\text { blockage of glutamate receptors; } \\
\text { Immuno-cytochemistry to measure } \\
\text { cytotoxicity }\end{array}$ & $\begin{array}{l}\text { Blockade of glutamate receptors } \\
\text { (NMDA and AMPA/kainite) may be } \\
\text { neuroprotective }\end{array}$ \\
\hline Forrest et al. [71] & Patients with mild IBD & $\begin{array}{l}\text { Measured serum concentrations of } \\
\text { purines and kynurenines }\end{array}$ & $\begin{array}{l}\text { Kynurenine modulation of gluta- } \\
\text { mate receptors is involved in the } \\
\text { symptoms of IBD }\end{array}$ \\
\hline
\end{tabular}

\section{Discussion}

The iterative approach used during discovery browsing mirrors the iteration observed in studies of complex problem solving [75] and is recognized more generally as an inherent part of the information seeking process [76-78], characterized as six stages: task initiation, selection, exploration, focus formulation, collection, and presentation $^{1}$. This work shows how predicates provided by SemRep and the interactive Semantic MEDLINE interface supports a user as they iterate between selection, exploration, and focus formulation steps.

Based on the results of this study, the statistical correlation found in clinical data [9] can be explained by an increase in glutamate due to IL-1 beta which is involved in the etiology of both IBD and epilepsy. To recapitulate the research that supports that claim, we first looked at IL-1 beta involvement with IBD and epilepsy individually. It is widely accepted that IL-1 beta is etiologically associated with IBD. Regarding epilepsy, there is considerable research suggesting that IL-1 beta is crucially involved in the mechanism of that disorder, and, further, that excess glutamate, being excitotoxic, also contributes to the etiology of epilepsy and seizure.

We next looked at research investigating the interaction of IL-1 beta and glutamate in epilepsy. Several studies based on both animal and human in vitro and in vivo studies suggest that IL-1 beta induces glutamate activity increasing glutamate, facilitating its receptors, and inhibiting its uptake by glial cells, although some studies report that IL-1 beta inhibits glutamate under their research conditions.

Glutamate plays an important role in several normal gastrointestinal functions, and some research suggests that excessive levels of glutamate contribute to disturbances. The strongest evidence for this is that the NMDA antagonist kynurenic acid has demonstrated therapeutic value in IBD models. Although it is widely accepted that IL-1 beta plays a crucial role in IBD, we did not find any studies investigating the interaction of IL-1 beta and glutamate in IBD. In the context of the rest of our findings, this would seem to be a potentially valuable direction to pursue. Figure 3 shows an overview of the hypothesis and supporting research.

Finally, we queried PubMed in an effort to determine whether the hypothesis that elevated glutamate levels due to IL-1 beta are part of the mechanism of both IBD and epilepsy is novel. Despite this supporting evidence, the PubMed query, ("interleukin 1" AND glutamate AND ("inflammatory bowel disease" OR colitis) AND (seizure OR epilepsy)) returned no citations, indicating the novelty of this hypothesis.

There are some limitations to our study. First, discovery browsing is a means of generating hypotheses, not of determining evidence. Therefore, hypotheses derived must be subjected to experimental investigation to determine their value and significance. Secondly, SemRep is not perfectly accurate; its precision is estimated to be about $75 \%$ (lower for predications involving cellular/molecular interactions) and its recall is lower (estimated to be approximately 50\% [25]). Note, however, that automatic summarization filters out some of the precision errors, and also that a precision error can still be useful in pinpointing MEDLINE citations that merit closer scrutiny (as shown in one of the examples above). On the other hand, by issuing queries directly to PubMed, in addition to Semantic MEDLINE, we aimed to mitigate the effect of recall errors. Lastly, our methodology relies solely on semantic predications and manual inspection of MEDLINE citations that they are extracted from. There is a wealth of taxonomic and relational knowledge which can be mined directly from UMLS and biomedical ontologies (e.g., Gene Ontology) and incorporated into discovery browsing to pinpoint other interesting associations. We plan to explore this integration in future work. 


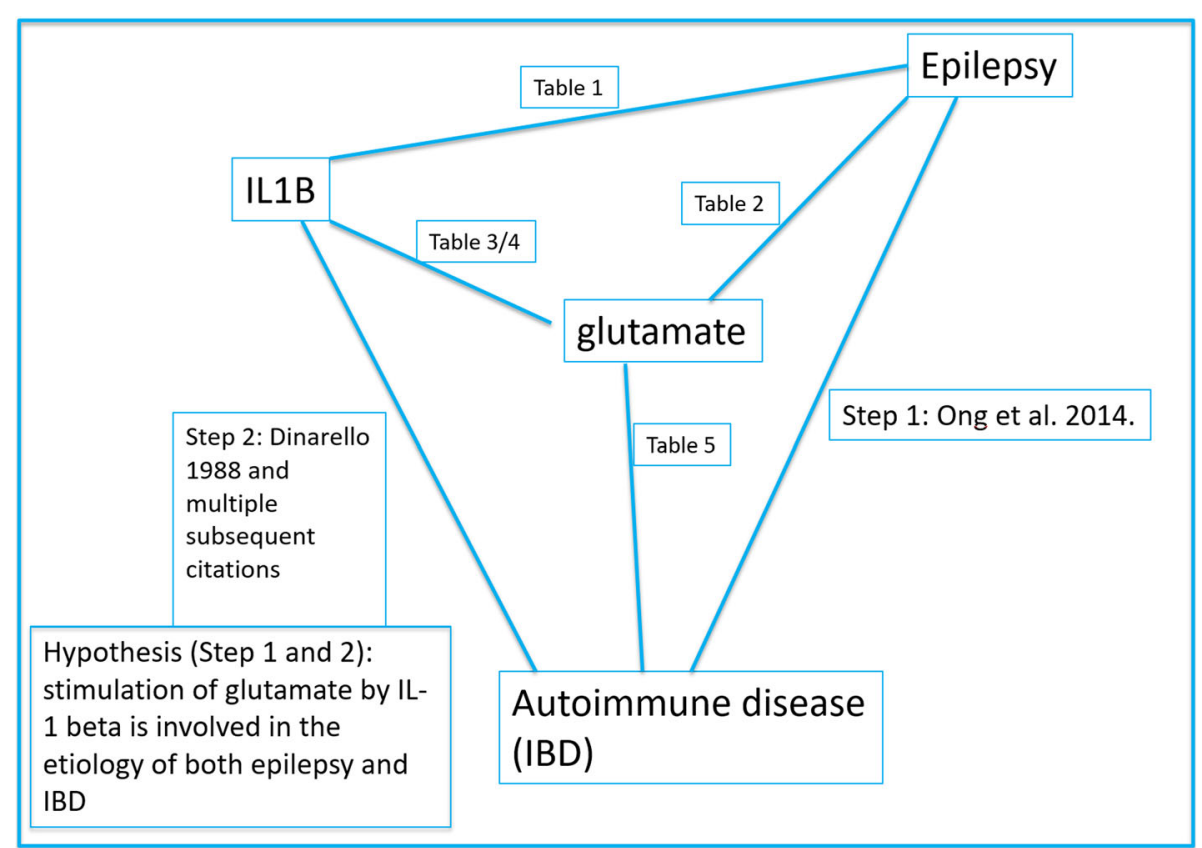

Fig. 3 Overview of the hypothesis and supporting research. Increase in glutamate due to IL-1 beta may be involved in the etiology of both IBD and epilepsy

\section{Conclusion}

Data-mining studies using population-scale data have the potential to identify novel correlations; however, they generally do not provide plausible explanations for these correlations. Although there is no single experiment that demonstrates the direct connection between interleukin and glutamate and inflammatory bowel disease or colitis, the discovery browsing approach used in this paper demonstrates that there is evidence available to support the mechanistic connection between the observation made in a population study [9] that epilepsy and IBD often co-occur and that inflammation is likely involved. We followed cooperative reciprocity in the discovery browsing methodology, which involves a complementary interaction between the user and Semantic MEDLINE and PubMed, with the former suggesting ideas to pursue and the latter two providing support or disconfirmation. Based on the results of this method, we proposed the hypothesis that IL-1 beta influence on glutamate levels is involved in the etiology of both epilepsy and IBD. This hypothesis can underpin the development of more effective therapeutic approaches for both epilepsy and IBD.

We conclude by observing that semantics-based discovery browsing is complementary to population-based correlation studies. The former provides depth (mechanism), while the latter provide breadth. It is possible to start with either and use the other for support. In this study we started with a correlation-based study and used discovery browsing to elucidate a mechanism. Hypotheses suggested by discovery browsing could also be supported with population studies.

\section{Endnote}

${ }^{1}$ Prior work that studied biomedical researchers as they systematically reviewed the literature also found that this process holds, with one additional step (synthesis) that occurs between the collection and presentation stages $[79,80]$.

\section{Abbreviations}

EHR: Electronic health record IBD: Inflammatory bowel disease IBS: Irritable bowel syndrome IL: Interleukin IL-1R1: Interleukin-1 receptor type 1 LBD: Literature-based discovery OVLT: OrganumRrganum vasculosum laminae terminalis UMLS: Unified medical language system

\section{Acknowledgements}

We acknowledge Kenneth Mandl and Mei-Sing Ong, whose research provided the impetus for our investigation.

\section{Funding}

This research was supported in part by the Intramural Research Program of the National Institutes of Health, National Library of Medicine.

\section{Availability of data and materials}

SemMedDB data used in this study is publicly available at https://skr3.nIm.nih. gov/SemMedDB/download/download.html.

\section{Authors' contributions}

TCR conceived of the study, performed the searches, and wrote the first draft of the manuscript. CLB, MJC, MF, CJZ, and HK contributed to discussions about the generated hypothesis. HK finalized the manuscript. All authors read, edited, and approved the manuscript.

Ethics approval and consent to participate Not applicable. 


\section{Consent for publication}

Not applicable.

\section{Competing interests}

The authors declare that they have no competing interests.

\section{Publisher's Note}

Springer Nature remains neutral with regard to jurisdictional claims in published maps and institutional affiliations.

\begin{abstract}
Author details
${ }^{1}$ Retired, Washington, DC, USA. ${ }^{2}$ School of Information Sciences, University of Illinois at Urbana-Champaign, 501 E Daniel Street, 61820 Champaign, IL, USA. ${ }^{3}$ Kaiser Permanente Southern California, 11975 El Camino Real, 92103, San Diego, CA, USA. ${ }^{4}$ Independent researcher, Rio de Janeiro, Brazil. ${ }^{5}$ Department of Comparative Medicine, Yale School of Medicine, 06520 New Haven, CT, USA. ${ }^{6}$ Lister Hill National Center for Biomedical Communications, U.S. National Library of Medicine, 8600 Rockville Pike, Bethesda, MD, USA.
\end{abstract}

\section{Received: 20 July 2018 Accepted: 16 November 2018} Published online: 27 December 2018

\section{References}

1. Ely JW, Osheroff JA, Ebell MH, Bergus GR, Levy BT, Chambliss ML, Evans ER Analysis of questions asked by family doctors regarding patient care. BMJ. 1999;319(7206):358-61.

2. Richardson WS, Wilson MC, Nishikawa J, Hayward RS. The well-built clinical question: a key to evidence-based decisions. ACP J Club. 1995;123(3):12.

3. Blake C. Evidence-based discovery. In: iConference 2015 Proceedings. 2015.

4. Rescher N. Peirce's Philosophy of Science: Critical Studies in His Theory of Induction \& Scientific Method. Notre Dame, IN: University of Notre Dame Press; 1978.

5. Jensen PB, Jensen $L$, Brunak S. Mining electronic health records: towards better research applications and clinical care. Nat Rev Genet. 2012;13(6):395.

6. Ryan PB, Madigan D, Stang PE, Marc Overhage J, Racoosin JA, Hartzema AG. Empirical assessment of methods for risk identification in healthcare data: results from the experiments of the observational medical outcomes partnership. Stat Med. 2012;31(30):4401-15.

7. Wilkowski B, Fiszman M, Miller CM, Hristovski D, Arabandi S, Rosemblat G, Rindflesch TC. Graph-based methods for discovery browsing with semantic predications. In: AMIA Annual Symposium Proceedings. Washington, DC: American Medical Informatics Association; 2011. p 1514-23.

8. Cairelli MJ, Miller CM, Fiszman M, Workman TE, Rindflesch TC. Semantic medline for discovery browsing: using semantic predications and the literature-based discovery paradigm to elucidate a mechanism for the obesity paradox. In: AMIA Annual Symposium Proceedings. Washington, DC: American Medical Informatics Association; 2013. p. 164-73.

9. Ong M-S, Kohane IS, Cai T, Gorman MP, Mandl KD. Population-level evidence for an autoimmune etiology of epilepsy. JAMA Neurol. 2014;71(5):569-74. https://doi.org/10.1001/jamaneurol.2014.188.

10. Meldrum BS. The role of glutamate in epilepsy and other cns disorders. Neurology. 1994;44(11 Suppl 8):S14-S23.

11. Manto M, Dalmau J, Didelot A, Rogemond V, Honnorat J. In vivo effects of antibodies from patients with anti-nmda receptor encephalitis: further evidence of synaptic glutamatergic dysfunction. Orphanet J Rare Dis. 2010;5(1):31. https://doi.org/10.1186/1750-1172-5-31.

12. Barker-Haliski M, White HS. Glutamatergic mechanisms associated with seizures and epilepsy. Cold Spring Harb Perspect Med. 2015;:5(8):022863.

13. Ravizza T, Gagliardi BA, Noè FM, de Boer K, Aronica E, Vezzani A. Innate and adaptive immunity during epileptogenesis and spontaneous seizures: evidence from experimental models and human temporal lobe epilepsy. Neurobiol Dis. 2008;29(1):142-60.

14. Aronica E, Crino PB. Inflammation in epilepsy: Clinical observations. Epilepsia. 52(s3):26-32. https://doi.org/10.1111/j.1528-1167.2011.03033.x.

15. Swanson DR. Fish oil, raynaud's syndrome, and undiscovered public knowledge. Perspect Biol Med. 1986;30(1):7-18.

16. Cory KA. Discovering hidden analogies in an online humanities database. Comput Hum. 1997;31(1):1-12.
17. Gordon M, Lindsay RK, Fan W. Literature-based discovery on the world wide web. ACM Trans Internet Technol (TOIT). 2002;2(4):261-75.

18. Ittipanuvat V, Fujita K, Sakata I, Kajikawa Y. Finding linkage between technology and social issue: A literature based discovery approach. J Eng Technol Manag. 2014;32:160-84.

19. Rindflesch TC, Fiszman M. The interaction of domain knowledge and linguistic structure in natural language processing: interpreting hypernymic propositions in biomedical text. J Biomed Inform. 2003;36(6): 462-77.

20. Lindberg DAB, Humphreys BL, McCray AT. The Unified Medical Language System. Methods Inf Med. 1993;32:281-91.

21. Bodenreider O. The Unified Medical Language System (UMLS): integrating biomedical terminology. Nucleic Acids Res. 2004;32(Database issue):267-70

22. Fiszman M, Rindflesch TC, Kilicoglu H. Abstraction summarization for managing the biomedical research literature. In: Proceedings of the HLT-NAACL Workshop on Computational Lexical Semantics. Boston: Association for Computational Linguistics; 2004. p. 76-83.

23. Ahlers CB, Fiszman M, Demner-Fushman D, Lang FM, Rindflesch TC. Extracting semantic predications from Medline citations for pharmacogenomics. In: Pacific Symposium on Biocomputing. Maui: World Scientific; 2007. p. 209-20.

24. Kilicoglu H, Fiszman M, Rodriguez A, Shin D, Ripple A, Rindflesch T. Semantic MEDLINE: A web application to manage the results of PubMed searches. In: Salakoski T, Schuhmann DR, Pyysalo S, editors. Proceedings of the Third International Symposium on Semantic Mining in Biomedicine (SMBM 2008), Turku, Finland. Turku: Turku Centre for Computer Science (TUCS); 2008. p. 69-76.

25. Kilicoglu H, Shin D, Fiszman M, Rosemblat G, Rindflesch TC. SemMedDB: a PubMed-scale repository of biomedical semantic predications. Bioinformatics. 2012;28(23):3158-60.

26. Miller CM, Rindflesch TC, Fiszman M, Hristovski D, Shin D, Rosemblat G, Zhang H, Strohl KP. A closed literature-based discovery technique finds a mechanistic link between hypogonadism and diminished sleep quality in aging men. Sleep. 2012;35(2):279-85.

27. Cohen T, Whitfield GK, Schvaneveldt RW, Mukund K, Rindflesch T. Epiphanet: an interactive tool to support biomedical discoveries. Biomed Discov Collab. 2010;5:22-44.

28. Hristovski D, Rindflesch T, Peterlin B. Using literature-based discovery to identify novel therapeutic approaches. Cardiovasc Hematol Agents Med Chem. 2013;11(1):14-24.

29. Smalheiser NR, Swanson DR. Using ARROWSMITH: a computer-assisted approach to formulating and assessing scientific hypotheses. Comput Methods Prog Biomed. 1998;57(3):149-53.

30. Pratt W, Yetisgen-Yildiz M. LitLinker: capturing connections across the biomedical literature. In: Proceedings of the 2 nd International Conference on Knowledge Capture. Sanibel Island: ACM; 2003. p. 105-12.

31. Aronson AR, Lang F-M. An overview of MetaMap: historical perspective and recent advances. J Am Med Inform Assoc (JAMIA). 2010;17(3):229-36.

32. Berlanga R, Jiménez-Ruiz $E$, Nebot $V$. Exploring and linking biomedical resources through multidimensional semantic spaces. BMC Bioinformatics. 2012;13(1):6.

33. Callahan A, Dumontier M, Shah NH. HyQue: evaluating hypotheses using Semantic Web technologies. In: Journal of Biomedical Semantics. BioMed Central; 2011. p. 3.

34. Bevivino G, Monteleone $G$. Advances in understanding the role of cytokines in inflammatory bowel disease. Expert Rev Gastroenterol Hepat. 2018;12(9):907-15.

35. Matin N, Tabatabaie O, Falsaperla R, Lubrano R, Pavone P, Mahmood F, Gullotta M, Serra A, Mauro PD, Cocuzza S, et al. Epilepsy and innate immune system: a possible immunogenic predisposition and related therapeutic implications. Hum Vaccines Immunotherapeutics. 2015;11(8): 2021-9.

36. Dinarello CA. Interleukin-1. Dig Dis Sci. 2013;33(3 Suppl):25-35.

37. Mahida YR, Wu K, Jewell D. Enhanced production of interleukin 1-beta by mononuclear cells isolated from mucosa with active ulcerative colitis of crohn's disease. Gut. 1989:30(6):835-8.

38. Casellas F, Papo M, Guarner F, Antolín M, Segura RM, Armengol JR, Malagelada J-R. Intracolonic release in vivo of interleukin-1 $\beta$ in chronic ulcerative colitis. Clin Sci. 1995;89(5):521-6.

39. Heresbach D, Alizadeh M, Dabadie A, Berre NL, Colombel JF, Yaouanq J, Bretagne JF, Semana G. Significance of interleukin-1 beta and 
interleukin-1 receptor antagonist genetic polymorphism in inflammatory bowel diseases. Am J Gastroenterol. 1997;92(7):1164-9.

40. Coccia M, Harrison OJ, Schiering C, Asquith MJ, Becher B, Powrie F, Maloy KJ. II-1 $\beta$ mediates chronic intestinal inflammation by promoting the accumulation of il-17a secreting innate lymphoid cells and cd4+ th 17 cells. J Exp Med. 2012;209(9):1595-609.

41. Li L, Liu Z, Yang X, Yan H, Bao S, Fei J. Bioluminescence imaging for il-1 $\beta$ expression in experimental colitis. Int J Inflamm. 2013;10(1):16. https://doi.org/10.1186/1476-9255-10-16.

42. Das UN. Inflammatory bowel disease as a disorder of an imbalance between pro-and anti-inflammatory molecules and deficiency of resolution bioactive lipids. Lipids Health Dis. 2016;15(1):11.

43. Rao R, Prakash A, Medhi B. Role of different cytokines and seizure susceptibility: a new dimension towards epilepsy research. Indian J Exp Biol. 2009;47(8):625-34.

44. Vezzani A, Moneta D, Conti M, Richichi C, Ravizza T, Luigi AD, Simoni M-GD, Sperk G, Andell-Jonsson S, Lundkvist J, Iverfeldt K, Bartfai T. Powerful anticonvulsant action of il-1 receptor antagonist on intracerebral injection and astrocytic overexpression in mice. Proc Natl Acad Sci U S A. 2000;97(21):11534-9.

45. Vezzani A, Conti M, De Luigi A, Ravizza T, Moneta D, Marchesi F, De Simoni MG. Interleukin-1 $\beta$ immunoreactivity and microglia are enhanced in the rat hippocampus by focal kainate application: functional evidence for enhancement of electrographic seizures. J Neurosci. 1999;19(12):5054-65.

46. Ravizza T, Vezzani A. Status epilepticus induces time-dependent neuronal and astrocytic expression of interleukin-1 receptor type $i$ in the rat limbic system. Neuroscience. 2006;137(1):301-8.

47. Zhen W, Qingying $L$, Changgeng Z. Effect of interleukin- $1 \beta$ on the variation of adenylyl cyclase expression in rats with seizures induced by I-glutamate. J Huazhong Univ Sci Technol [Med Sci]. 2004;24(6):540-2.

48. Pernot $F$, Heinrich $C P$, Barbier $L$, Peinnequin $A$, Carpentier $P$, Dhote F, Baille V, Beaup C, Depaulis A, Dorandeu F. Inflammatory changes during epileptogenesis and spontaneous seizures in a mouse model of mesiotemporal lobe epilepsy. Epilepsia. 2011;52(12):2315-25. https://doi. org/10.1111/j.1528-1167.2011.03273.x.

49. Claycomb RJ, Hewett SJ, Hewett JA. Neuromodulatory role of endogenous interleukin- $1 \beta$ in acute seizures: possible contribution of cyclooxygenase-2. Neurobiol Dis. 2012;45(1):234-42.

50. Juhász C, Hu J, Xuan Y, Chugani HT. Imaging increased glutamate in children with sturge-weber syndrome: Association with epilepsy severity. Epilepsy Res. 2016;122:66-72. https://doi.org/10.1016/j.eplepsyres.2016. 02.010.

51. Bodensteiner JB, Roach ES. Sturge-Weber Syndrome. Mt. Freedom: Sturge-Weber Foundation; 1999

52. Cavus I, Romanyshyn JC, Kennard JT, Farooque P, Williamson AE, Eid T, Spencer SS, Duckrow RB, Dziura JD, Spencer DD. Elevated basal glutamate and unchanged glutamine and gaba in refractory epilepsy: Microdialysis study of 79 patients at the yale epilepsy surgery program. Ann Neurol. 2016;80(1):35-45. https://doi.org/10.1002/ana.24673.

53. Perez EL, Lauritzen F, Wang Y, Lee T-SW, Kang D, Zaveri HP, Chaudhry FA, Ottersen OP, Bergersen LH, Eid T. Evidence for astrocytes as a potential source of the glutamate excess in temporal lobe epilepsy. Neurobiol Dis. 2012;47(3):331-7. https://doi.org/10.1016/j.nbd.2012.05. 010.

54. Xiaoqin Z, Zhengli L, Changgeng Z, Xiaojing W, Li L. Changes in behavior and amino acid neurotransmitters in the brain of rats with seizure induced by il-1beta or il-6. J Huazhong Univ Sci Technol [Med Sci]. 2005;25(3):236-9.

55. Donnelly S, Loscher CR, Mills K, Lynch M. Glycerol-induced seizure: involvement of il-1 beta and glutamate. Neuroreport. 1999;10(9):1821-5.

56. Hu S, Sheng W, Ehrlich LC, Peterson PK, Chao CC. Cytokine effects on glutamate uptake by human astrocytes. Neuroimmunomodulation. 2000;7(3):153-9.

57. Huang K-F, Huang W-T, Lin K-C, Lin M-t, Chang C-P. Interleukin-1 receptor antagonist inhibits the release of glutamate, hydroxyl radicals, and prostaglandin e(2) in the hypothalamus during pyrogen-induced fever in rabbits. Eur J Pharmacol. 2010;629(1-3):125-31. https://doi.org/10. 1016/j.ejphar.2009.11.060

58. Mascarucci P, Perego C, Terrazzino S, Simoni M-GD. Glutamate release in the nucleus tractus solitarius induced by peripheral lipopolysaccharide and interleukin-1 beta. Neuroscience. 1998;86(4):1285-90.
59. Murray C, McGahon BM, McBennett ST, Lynch M. Interleukin-1 beta inhibits glutamate release in hippocampus of young, but not aged, rats. Neurobiol Aging. 1997;18(3):343-8.

60. Gonzalez P, Machado I, Vilcaes A, Caruso C, Roth GA, Schiöth H, Lasaga M, Scimonelli T. Molecular mechanisms involved in interleukin 1-beta (il-1 $\beta$ )-induced memory impairment. modulation by alpha-melanocyte-stimulating hormone ( $\alpha$-msh). Brain Behav Immun. 2013;34:141-50. https://doi.org/10.1016/j.bbi.2013.08.007.

61. Casamenti F, Prosperi C, Scali C, Giovannelli L, Colivicchi M, Faussone-Pellegrini M, Pepeu G. Interleukin- $1 \beta$ activates forebrain glial cells and increases nitric oxide production and cortical glutamate and gaba release in vivo: implications for alzheimer's disease. Neuroscience. 1999;91(3):831-42.

62. Prow NA, Irani DN. The inflammatory cytokine, interleukin-1 beta, mediates loss of astroglial glutamate transport and drives excitotoxic motor neuron injury in the spinal cord during acute viral encephalomyelitis. J Neurochem. 2008;105(4):1276-86. https://doi.org/ 10.1111/j.1471-4159.2008.05230.x.

63. Fogal B, Li J, Lobner D, McCullough LD, Hewett SJ. System x(c)-activity and astrocytes are necessary for interleukin-1 beta-mediated hypoxic neuronal injury. J Neurosci. 2007;27(38):10094-105.

64. Yan $\mathrm{X}$, Weng $\mathrm{H}-\mathrm{R}$. Endogenous interleukin- $1 \beta$ in neuropathic rats enhances glutamate release from the primary afferents in the spinal dorsal horn through coupling with presynaptic n-methyl-d-aspartic acid receptors. J Biol Chem. 2013;288(42):30544-57. https://doi.org/10.1074/ jbc.M113.495465.

65. Yan X, Yadav R, Gao M, Weng H-R. Interleukin-1 beta enhances endocytosis of glial glutamate transporters in the spinal dorsal horn through activating protein kinase c. Glia. 2014;62(7):1093-109. https://doi. org/10.1002/glia.22665.

66. Julio-Pieper M, O'Connor RM, Dinan TG, Cryan JF. Regulation of the brain-gut axis by group iii metabotropic glutamate receptors. Eur J Pharmacol. 2013;698(1-3):19-30.

67. Hornby P. Receptors and transmission in the brain-gut axis. ii. excitatory amino acid receptors in the brain-gut axis. Am J Physiol Gastrointest Liver Physiol. 2001;280(6):1055-60.

68. Clarke G, Fitzgerald PJ, Cryan JF, Cassidy EM, Quigley EMM, Dinan TG. Tryptophan degradation in irritable bowel syndrome: evidence of indoleamine 2,3-dioxygenase activation in a male cohort. In: BMC Gastroenterology; 2009. p. 6. https://doi.org/10.1186/1471-230X-9-6.

69. Varga G, Érces D, Fazekas B, Fülöp M, Kovács T, Kaszaki J, Fülöp F, Vécsei L, Boros M. N-methyl-d-aspartate receptor antagonism decreases motility and inflammatory activation in the early phase of acute experimental colitis in the rat. Neurogastroenterol Motil. 2010;22(2): 217-2568. https://doi.org/10.1111/j.1365-2982.2009.01390.x.

70. Carpanese E, Moretto P, Filpa V, Marchet S, Moro E, Crema F, Frigo G, Giaroni C. Antagonism of ionotropic glutamate receptors attenuates chemical ischemia-induced injury in rat primary cultured myenteric ganglia. PloS ONE. 2014;9(11):113613. https://doi.org/10.1371/journal. pone.0113613.

71. Forrest CM, Youd P, Kennedy A, Gould SR, Darlington LG, Stone TW. Purine, kynurenine, neopterin and lipid peroxidation levels in inflammatory bowel disease. J Biomed Sci. 2002;9(5):436-42.

72. Saperas ES, Yang H, Rivier C, Taché Y. Central action of recombinant interleukin-1 to inhibit acid secretion in rats. Gastroenterology. 1990;99(6): 1599-606.

73. Morrow NS, Quinonez G, Weiner H, Tache Y, Garrick T. Interleukin-1 beta in the dorsal vagal complex inhibits trh analogue-induced stimulation of gastric contractility. Am J Physiol Gastrointest Liver Physiol. 1995;269(2 Pt 1):196-202.

74. Qu Y, Dang S, Hou P. Gene methylation in gastric cancer. Clinica chimica acta. 2013;424:53-65. https://doi.org/10.1016/j.cca.2013.05.002.

75. Mirel B, Tonks JS, Song J, Meng F, Xuan W, Ameziane R. Studying PubMed usages in the field for complex problem solving: Implications for tool design. J Assoc Inf Sci Technol. 2013;64(5):874-92.

76. Ellis D, Haugan M. Modelling the information seeking patterns of engineers and research scientists in an industrial environment. J Doc. 1997;53(4):384-403.

77. Kuhlthau CC. Inside the search process: Information seeking from the user's perspective. J Am Soc Inf Sci. 1991;42(5):361. 
78. Bates MJ. The design of browsing and berrypicking techniques for the online search interface. Online Rev. 1989;13(5):407-24.

79. Blake C, Pratt W. Collaborative information synthesis i: A model of information behaviors of scientists in medicine and public health. J Am Soc Inf Sci Technol. 2006;57(13):1740-9.

80. Blake C, Pratt W. Collaborative information synthesis ii:

Recommendations for information systems to support synthesis activities. J Am Soc Inf Sci Technol. 2006;57(14):1888-95.

- fast, convenient online submission

- thorough peer review by experienced researchers in your field

- rapid publication on acceptance

- support for research data, including large and complex data types

- gold Open Access which fosters wider collaboration and increased citations

- maximum visibility for your research: over $100 \mathrm{M}$ website views per year

At $B M C$, research is always in progress.

Learn more biomedcentral.com/submissions 